\title{
ECOS DO PENSAMENTO SAUSSURIANO NA PROPOSTA DE UMA TEORIA PARA O FUNCIONAMENTO DA LINGUAGEM A PARTIR DAS RELAÇÕES METAFÓRICAS E METONÍMICAS
}

DOI: $10.48075 / R I . V 22 I 2.25183$

RESUMO: Este trabalho consiste numa tentativa de colocar em relevo a importância do ensino saussuriano para as reflexões teóricas de Roman Jakobson acerca de uma teoria que pudesse explicar, a partir dos princípios gerais da linguística, o funcionamento da linguagem. É importante dizer que não é nossa intenção retomar todo o pensamento de Saussure, tampouco o de Jakobson, mas destacar o caminho feito por este último para fundar uma proposta de investigação do funcionamento da linguagem a partir da observação de dois mecanismos de elaboração do discurso: combinação e seleção. Apresentamos alguns pontos propostos por Saussure a respeito da Linguística Diacrônica e da Linguística Sincrônica, e a crítica de Jakobson a essa secessão no Curso de Linguística Geral. Dessas duas linguísticas focalizamos, especialmente, a última, visto ter sido o estudo sincrônico da língua que permitiu a proposição das relações sintagmáticas e associativas e auxiliou o estudo de Jakobson sobre as afasias. Assim, o ensaio presente focaliza a relevância da reflexão jakobsoniana sobre a linguagem de um ponto de vista funcional e seus processos estruturadores, com vista ao reconhecimento dos polos metafórico e metonímico como eixos que permitem explicar a linguagem em movimento, no processo de dissolução ou constituição.

Palavras-chave: Estruturalismo Linguístico; Funcionamento da Linguagem; Saussure; Jakobson.

\section{ECHOES OF SAUSSURIAN THOUGHT IN THE PROPOSAL OF A THEORY FOR THE OPERATION OF LANGUAGE FROM ONWARDS THE RELATIONS METAPHORIC AND METONYMIC}

ABSTRACT: This work is an attempt to highlight the importance of Saussurian teaching for Roman Jakobson's theoretical reflections on a theory that could explain, from the general principles of linguistics, the functioning of language. It is important to say that it is not our intention to resume all Saussure's thought, nor that of Jakobson, but to highlight the path taken by the latter to found a proposal for investigating the functioning of language from the

\footnotetext{
${ }^{1}$ Doutora e Mestre em Ciências da Linguagem pela Universidade Católica de Pernambuco (UNICAP). Professora da Rede Pública de Ensino de Pernambuco. E-mail: magdapcarvalho@hotmail.com
} 
observation of two discourse elaboration mechanisms: combination and selection. We present some points proposed by Saussure regarding Diachronic Linguistics and Synchronic Linguistics, and Jakobson's critique of this secession in the General Linguistics Course. We focus, in particular, the last, since it was the synchronous study of the language that allowed the proposition of syntagmatic and associative relations and helped Jakobson's study of aphasias. Thus, the present essay focuses on the relevance of Jakobsonian reflection on language from a functional point of view and its structuring processes, with a view to recognizing metaphorical and metonymic poles as axes that allow explaining language in movement, in the process of dissolution or constitution.

Keywords: Linguistic Structuralism; Language Functioning; Saussure; Jakobson.

\section{INTRODUÇÃO}

É a partir da noção de língua como sistema articulado e relacional, em que cada elemento do sistema se define negativamente pelas diferenças que estabelece com todos os outros elementos, que a proposta do linguista Ferdinand de Saussure, em seu Curso de Linguística Geral, “representa 'um corte' em relação a todo pensamento linguístico e à tradição metafísica que o precederam" (LIER-DE VITTO, 2016, p. 55). E apesar de Saussure não ter tido a intenção de constituir um gesto teórico, reconhecemos, a partir de suas reflexões, a instalação de um saber que influenciou diferentes pensadores e diferentes campos das Ciências Humanas.

Dentre os temas tratados no Curso, seguindo a perspectiva de que a língua é um sistema que atua a partir das relações e das diferenças entre seus elementos, Saussure apresenta explicações sobre duas esferas distintas indispensáveis para a vida da língua, que atuam sobre suas unidades constitutivas quando essas estão no discurso ${ }^{2}$ ou fora dele.

No discurso, segundo Saussure (2006), os termos estabelecem relações baseadas na linearidade da língua. Essa característica da língua exclui a possibilidade de dois elementos serem pronunciados ao mesmo tempo, em virtude de estarem alinhados na cadeia da fala. Esses elementos, opostos entre si numa extensão espacial, são tratados por Saussure como sintagmas, em que "um termo só adquire seu valor porque se opõe ao que o precede ou ao que o segue, ou a ambos" (SAUSSURE, 2006, p. 142), constituindo, assim, uma relação de combinação entre os signos in praesentia.

\footnotetext{
${ }^{2}$ Cabe ressaltar que esse termo, no texto do Curso de Linguística Geral, refere-se às combinações de sintagmas empregadas na fala.
} 
Fora do discurso, as relações entre os elementos linguísticos, de acordo com Saussure (2006, p. 143), "não têm por base a extensão; sua sede está no cérebro" e, por isso, ocorrem por meio de associações mentais entre um determinado elemento linguístico e todos os outros ausentes que poderiam substituí-lo. Nesse aspecto, a associação une termos presentes na cadeia discursiva a termos que estão ausentes do contexto sintático, mas que se associam, in absentia, a outros pela aproximação da estrutura da palavra (radical e afixo), pela significação (analogia dos significados), pela semelhança de traços sonoros, entre outros, viabilizando, dessa maneira, a criação de diversas séries associativas.

Dessa forma, o funcionamento da língua como um "jogo de oposições dentro do sistema" (SAUSSURE, 2006, p. 141) consiste na associação, combinação e exclusão entre os elementos linguísticos, fenômeno que permite considerar a língua como um sistema que tem ordem própria, o que faz o pensamento saussuriano ser "um, e não 'mais um' na história das ideias linguísticas" (LIER-DE VITTO, 2016, p. 55, grifo da autora).

Estamos cientes de que o pensamento saussuriano vai muito além do ponto brevemente apresentado aqui, uma vez que o Curso de Linguística Geral representa uma ruptura epistemológica e pode ser considerado “como um texto 'fundador' de uma ciência nova" (NORMAND, 2009, p. 118). No entanto, tendo em vista que nosso interesse é colocar em destaque como o ensino saussuriano reverberou na proposta do linguista russo Roman Jakobson no que se refere à concepção de uma teoria para o funcionamento da linguagem, não nos debruçaremos sobre outros pontos do Curso, embora reconheçamos a importância deles para os diferentes estudos das ciências da linguagem.

Contudo, é importante ressaltar que, apesar de o pensamento saussuriano ter sido fundamental para a formalização dos estudos fonológicos e, especialmente, para o estudo das afasias, Jakobson não deixou de criticar o ensino saussuriano no que diz respeito à questão do tempo na língua, isto é, ao que Saussure chamou de Linguística sincrônica e Linguística diacrônica, "duas ordens de fenômenos relativos ao mesmo objeto" (SAUSSURE, 2006, p. 96). 
Diante disso, acreditamos que é importante destacar a avaliação de Jakobson sobre essas duas ordens (Linguística sincrônica e Linguística diacrônica) apresentadas por Saussure.

\section{CRÍTICA AO PENSAMENTO SAUSSURIANO}

Dentre os temas tratados no Curso, Saussure (2006) chama atenção para o fato de que a linguagem implica ao mesmo tempo um sistema estabelecido (sincrônico) e uma evolução (diacrônica). Nesse sentido, a linguagem pode ser observada do ponto de vista estático e também do evolutivo.

Saussure explica que na oposição entre esses dois pontos de vista, os fatos diacrônicos não objetivam assinalar um valor com outro signo, nem tendem a alterar o sistema. Os fatos sincrônicos, por sua vez, apelam sempre para dois termos simultâneos, o que lhe permite afirmar que "a língua é um sistema do qual todas as partes podem e devem ser consideradas em sua solidariedade sincrônica" (SAUSSURE, 2006, p. 102).

Jakobson, em seus "Diálogos" com Krystyna Pomorska (1985), diz que o primeiro contato com o ensino sobre sincronia e diacronia da língua fez saltar aos olhos tanto a terminologia quanto a teorização de Saussure sobre esses termos.

A crítica de Jakobson sobre esse ponto da teoria saussuriana refere-se à fragilidade dos conceitos (de sincronia e diacronia), pois em seu entendimento "a sincronia contém inúmeros elementos dinâmicos, que devem ser levados em conta quando há uma aproximação sincrônica" (JAKOBSON, 1985, p. 62).

Sendo a língua, no dizer de Saussure, um sistema cujas partes são consideradas em sua solidariedade sincrônica, e sendo a sincronia, no entendimento de Jakobson, dinâmica, a análise diacrônica, para este último, não pode e não deve se limitar apenas às modificações da língua, mas deve também levar em consideração os fatos estáticos, pois tentar reduzir as mudanças ao domínio da diacronia contradiz profundamente toda a expectativa linguística.

Por outro lado, Jakobson (1985) reconhece que qualquer modificação na língua ocorre, em primeiro lugar, no plano da sincronia e, desse modo, apenas os resultados das modificações são concedidos à diacronia. Diante disso, embora a ideologia saussuriana excluísse qualquer compatibilidade dos dois aspectos do tempo 
(simultaneidade e sucessão), Jakobson admite que a melhor maneira de conhecer a essência e o caráter de uma língua é a análise sincrônica dos fatos atuais.

Com isso, é possível compreender que a tese saussuriana de língua como sistema estabelecido a partir do ponto de vista sincrônico, apesar de ser criticada, foi, também, de certa maneira, o que ajudou Jakobson em suas formulações teóricas, embora sua proposta não seja a de língua como sistema de valores relativos, mas como um sistema funcional, que vai além da frase.

\section{SOBRE AS RELAÇÕES IN PRAESENTIA E IN ABSENTIA NO MOVIMENTO TEÓRICO} JAKOBSONIANO

Jakobson entende que a noção de língua como sistema foi o grande mérito de Saussure, uma vez que o mestre genebrino colocou "em primeiro plano o estudo do sistema da língua em seu conjunto na relação de todas as suas partes componentes" (JAKOBSON, 1985, p. 63). Apesar disso, a proposição do caráter linear do signo linguístico, para esse estudioso $(1985,64)$, trata-se de um caso de reducionismo à pura linearidade e suprime "qualquer possibilidade de se conceber o fonema como um feixe de aspectos distintivos simultâneos", o que, em sua compreensão, representa um empobrecimento da realidade linguística analisável.

É relevante lembrar que a presença de um som determinado, segundo Saussure em seus "Escritos",

só tem valor por oposição com outros sons presentes; e é essa a primeira aplicação [...], do princípio das OPOSIÇÕES, ou dos VALORES RECÍPROCOS, ou das QUANTIDADES NEGATIVAS e RELATIVAS que criam um estado de língua (SAUSSURE, 2004, p. 27, destaque do autor).

Nessa perspectiva, a tese das oposições, que dá consistência à teoria do valor e, consequentemente, ao princípio fundador do sistema da língua, foi admitida por Jakobson quando esse linguista encontrou, nas relações de combinação de termos in praesentia e de associação de termos in absentia, bases para abordar a metáfora e a metonímia como princípio do funcionamento geral da linguagem e, com isso, fundar um campo de investigação sobre o discurso. 
Cumpre sublinhar que, embora essas duas figuras de estilo (metáfora e metonímia) apareçam nas discussões de Jakobson desde os anos vinte, em seus estudos sobre poética e teoria da arte, foi em seus experimentos para a determinação das síndromes linguísticas das diferentes afasias, em meados dos anos cinquenta, que esse estudioso encontrou na metáfora e na metonímia apoio para desenvolver "um estudo linguístico da afasia" (JAKOBSON, 1985, p. 129).

Em seu texto "Dois aspectos de linguagem e dois tipos de afasia" (2008), Jakobson afirma que os distúrbios da fala consistem numa desordem, maior ou menor, das associações por similaridade ou por contiguidade. No caso da desorganização de similaridade, o autor explica que, devido a uma deterioração da metalinguagem, o afásico desse grupo é incapaz de dizer uma palavra isoladamente. Diante disso, o contexto de produção constitui fator indispensável e decisivo, pois permite ao paciente utilizar termos que se encontrem em relação de contiguidade com os termos solicitados pelo contexto.

A desorganização de contiguidade consiste na "deterioração da capacidade de construir proposições ou, em termos mais gerais, de combinar entidades linguísticas mais simples em unidades mais complexas" (JAKOBSON, 2008, p. 50). Nesse caso, a palavra é uma entidade preservada e, desse modo, o afásico tem dificuldade para organizar sintaticamente as palavras e adequá-las ao contexto, o que caracteriza uma deficiência na utilização da combinação e contextura. Segundo Jakobson (2008, p. 51), "quanto menos uma palavra depender gramaticalmente do contexto, tanto mais forte será sua persistência no discurso dos afásicos com distúrbio da função de contiguidade".

O autor explica que

em alguns casos, são os encadeamentos metafóricos da fala que se deterioram, em outros, os encadeamentos metonímicos; das duas operações fundamentais da fala, é a seleção (o eixo paradigmático) que sofre no primeiro caso, e a combinação (o eixo sintagmático), no segundo (JAKOBSON, 1985, p. 125-126).

Para ilustrar, Jakobson (2008, p. 49) diz que, quando a capacidade de seleção é afetada, um signo "que aparece ordinariamente ao mesmo tempo que outro signo [...] pode ser utilizado no lugar desse signo". Nesse sentido, a palavra "garfo" pode ser substituída por outra palavra do mesmo campo semântico, por exemplo, pela palavra 
"faca". De outra parte, quando a capacidade de combinação é comprometida, o sujeito é incapaz de dizer uma palavra fora do contexto. Nesse caso, "a extensão e a variedade das frases diminuem. [...]. A ordem das palavras se torna caótica; os vínculos de coordenação e subordinação gramatical, [...] dissolvem-se" (JAKOBSON, 2008, p. 51).

Ao tratar sobre o duplo caráter da linguagem, Jakobson (2008) afirma que a fala exige a seleção de certas entidades linguísticas, que se combina em unidades complexas de uma mesma língua. Diante disso, o autor afirma que todo signo implica dois modos de arranjo, a saber, o arranjo de combinação e o arranjo de seleção. O primeiro arranjo consiste na articulação das unidades linguísticas associadas no sistema, o que lhe confere estatuto de contiguidade. Para o autor (2008, p. 39), "isso significa que qualquer unidade linguística serve, ao mesmo tempo, de contexto para unidades mais simples e/ou encontra seu próprio contexto em uma unidade linguística mais complexa", quer dizer, as unidades estão associadas no código ou na mensagem.

Já o segundo arranjo, seleção, refere-se à substituição de termos alternativos associados no sistema linguístico, implicando a "possibilidade de substituir um pelo outro, equivalente ao primeiro num aspecto e diferente em outro" (JAKOBSON, 2008, p. 40), aspecto que lhe concede estatuto de similaridade. Esses arranjos, tal como as relações sintagmáticas e associativas da teoria saussuriana, aparecem in praesentia e in absentia respectivamente, e Jakobson reconhece que "o papel que estas duas operações desempenham na linguagem foi claramente percebido por Ferdinand de Saussure" (JAKOBSON, 2008, p. 40).

Diante dessa reinterpretação das relações in praesentia e in absentia observamos como a reflexão saussuriana ecoa no pensamento jakobsoniano, produzindo algo novo. Isso porque ao redimensionar essas relações, acrescentando-lhes as ideias de combinação/contiguidade para a primeira, e de substituição/similaridade para a segunda, Jakobson não trata mais das relações in praesentia e in absentia em si, mas de um movimento próprio dessas relações. Assim, a leitura de Jakobson das relações in absentia e in praesentia e sua reinterpretação como polos metafórico e metonímico permite-nos dizer que as formulações linguísticas de gênese saussuriana influenciaram a proposta de uma teoria para o funcionamento da linguagem. 
Para concluir, reconhecemos que o grande feito de Jakobson foi associar a metáfora ao distúrbio de similaridade e a metonímia ao distúrbio de contiguidade e colocá-las como "polos" ou, mais acertadamente, como "processos" que permitem observar o constante movimento da linguagem, quando não há distúrbio de linguagem, ou a prevalência de um processo sobre o outro, em casos de dissolução da linguagem.

Nesse sentido, é diante dessa reinterpretação, ou melhor, do eco da proposta saussuriana de relações associativas e sintagmáticas, que podemos olhar a linguagem em dissolução para compreender a linguagem em estado nascente, em ato e em evolução, isto é, a linguagem em funcionamento.

\section{REFERÊNCIAS}

JAKOBSON, R.; POMORSKA, K. Diálogos. São Paulo: Cultrix, 1985.

JAKOBSON, R. Linguística e Comunicação. 21.ed. São Paulo: Editora Cultrix, 2008.

LIER-DE VITTO, M. F. O objeto da linguística: um convite à releitura. Revista Cult, n. 216, p. 54-57, setembro 2016.

NORMAND, C. Saussure. São Paulo: Estação da Liberdade, 2009.

SAUSSURE, F. Escritos de Linguística Geral. São Paulo: Cultrix, 2004.

SAUSSURE, F. Curso de Linguística Geral. 27.ed. São Paulo: Cultrix, 2006.

Recebido em 08 de junho de 2020.

Aceito em 13 de agosto de 2020 